Artículo

\title{
En búsqueda dell enemigo: las representaciones del escenario bélico de la Guerra de Malvinas en los nuevos libros de texto (2006 - en busca)
}

\author{
In search of the enemy: representations of the war \\ scenario of the Malvinas' war in the new textbooks \\ (2006-present)
}

\author{
Bottazzi, Florencia
}

Florencia Bottazzi bottazziflorencia@gmail.com Universidad Nacional de La Plata, Argentina

\author{
Clio \& Asociados. La historia enseñada \\ Universidad Nacional del Litoral, Argentina \\ ISSN: 2362-3063 \\ Periodicidad: Semestral \\ núm. 32, 2021 \\ clio@fhuc.unl.edu.ar \\ Recepción: 27 Febrero 2021 \\ Aprobación: 13 Mayo 2021
}

URL: http://portal.amelica.org/ameli/jatsRepo/111/1112174006/ index.html

DOI: https://doi.org/10.14409/cya.v0i32.10113
Resumen: La guerra de Malvinas, lejos de ser un hecho del pasado reciente cristalizado homogéneamente en aquel complejo denominado memoria colectiva, es una cuestión que continúa atravesando al conjunto de la sociedad y persiste en la disputa de significaciones. Históricamente la institución escolar ha tenido un rol esencial en esta disputa, construyendo lazos imperantes con la identidad nacional en general y con Malvinas en particular. No obstante, estas relaciones y discursos no han sido estáticos y homogéneos, sino que se han visto modificados acorde a los nuevos esquemas, normas y reglas del tiempo histórico actual. En este trabajo nos proponemos analizar las representaciones del escenario bélico de Malvinas en esta parte fundamental del entramado social a partir del libro de texto como objeto de estudio, durante el nuevo período inaugurado por la Ley de Educación Nacional (LEN). A partir de la noción de discurso social, revistaremos las representaciones de los contendientes de la Guerra y cómo contribuyen a significar la Historia.

Palabras clave: Guerra de Malvinas, discurso social, libros de texto, enseñanza de la Historia, propuestas editoriales.

\begin{abstract}
The Malvinas war, far from being a fact of the recent past homogeneously crystallized in that complex called collective memory, is an issue that gets through a whole society and persists in the dispute over meanings. Historically, the school institution has played an essential role in this dispute, building prevailing ties with the national identity in general and with Malvinas Island in particular. However, these relationships and discourses have not been static and homogeneous, but have been modified according to the new schemes, norms and rules of current historical time. In this work we propose to analyze the representations of the Malvinas war scene in this fundamental part of the social structured based on the textbook as an object of study, during the new period inaugurated by the National Education Law (LEN). Starting from the notion of social discourse, we will review the representations of the contenders of the $W$ ar and how they contribute to signify History.
\end{abstract}

Keywords: Malvinas War, social discourse, textbooks, History teaching, editorial proposals. 


\section{Introducción}

Próximos al cuarenta aniversario de la Guerra de Malvinas, podemos afirmar la vigencia de este episodio de la historia reciente como un suceso aún no clausurado y en disputa que merece ser indagado. ${ }^{2}$ Este carácter se manifiesta en las copiosas y dispares representaciones de la Guerra que atraviesan transversalmente a la sociedad argentina: los medios de comunicación, la música, el teatro, los monumentos a la memoria, la literatura, los discursos escolares, la academia.

De esta manera, Malvinas se vuelve un complejo polisémico que articula diversas visiones y sentidos: causa popular, guerra absurda, imperialismo, terrorismo de Estado, héroes, víctimas, apoyo popular, manipulación, soberanía, derechos humanos son algunas de las condensaciones semánticas que de allí se desprenden. Por lo tanto, se complejiza poder hablar de una sola interpretación de la Guerra y, por el contrario, es necesario reparar en las lecturas muchas veces fragmentarias y fragmentantes. ${ }^{3}$

A fin de intentar comprender su carácter polémico y en disputa resulta necesario recapitular las características que permiten pensar a la Guerra de Malvinas como un fenómeno particular en la historia argentina reciente. Siguiendo a Guber (2019b) existen al menos cuatro puntos que le dan carácter inédito a la Guerra. En el aspecto bélico, se trata de la única guerra del siglo que tiene a Argentina como principal contendiente, en este caso, contra Reino Unido. En cuanto al centro de operaciones, dentro de las filas de combatientes participan soldados conscriptos -generación 62 y 63- que se encontraban realizando el servicio militar obligatorio o lo habían terminado hacía poco tiempo. A su vez, la Guerra se destaca también por sus fuertes implicancias sociales: la decisión de recuperar las islas contó con el apoyo generalizado de amplios sectores de la sociedad; mientras que, la derrota declarada, precipitó el fin del autoproclamado "Proceso de Reorganización Nacional", gobierno de facto que había gobernado en Argentina desde 1976.

Lo interesante de estas particularidades son las posibilidades de interpretación y las distintas visiones de la Guerra que suscitan. En ese sentido, el discurso social resulta una valiosa herramienta de abordaje. El discurso social en tanto que entramado amplio en el que se inserta todo lo dicho en determinada época y contexto social (Angenot, 2012) posee determinadas normas y reglas que delinean lo decible y lo pensable. Es decir, el discurso social no es un rumor o collage de representaciones superpuestas azarosamente. Por el contrario, si estudiamos detenidamente toda esa masa discursiva en un corte sincrónico, seremos capaces de detectar esos "hilos" que construyen un entramado coherente en el que ciertas visiones de mundo se imponen por encima de otras.

A esta estructura subyacente a todo el decir y pensar de una sociedad es a lo que se conoce como hegemonía discursiva. En términos Angenot: "un conjunto de mecanismos unificadores y reguladores que aseguran a la vez la división del trabajo discursivo y un grado de homogeneización de retóricas, tópicas y doxas transdiscursivas" (Angenot, 2012:31). A su vez, la hegemonía también produce el memorial y la conjuración del olvido en una sociedad. En este punto, puede 
entenderse la disputa en torno al pasado reciente y la memoria colectiva que es, ante todo, una construcción intencional y selectiva.

Dicho de otra forma, las maneras en la que se relacionan y ponen en juego los distintos rasgos que hacen de la Guerra de Malvinas un episodio particular no pueden pensarse por fuera de la hegemonía discursiva del momento. Es a partir de estos parámetros y normas que se regulan las visiones posibles de la Guerra y se legitiman unas en detrimento de otras. A su vez, el discurso no es el mero soporte de la memoria, sino que es el responsable de construirla. Es decir, las configuraciones discursivas son significativas en tanto que vehiculizan determinadas visiones en detrimento de otras. En ese sentido, atender a las elecciones discursivas en el nivel microtextual -elecciones léxicas, estrategias sintácticas, etc.- no es accesorio sino fundamental para atender a las operaciones de construcción de sentido de cada discurso.

La institución escolar ha jugado un rol trascendental -pero no único- en la circulación y puesta en valor de las distintas visiones respecto a la Guerra. En efecto, la escuela había sido uno de los principales actores en la configuración de Malvinas como causa nacional antes de la Guerra. Si bien con la sanción de la Ley Federal de Educación ( $\mathrm{n}^{\circ} 24.195$ ) en 1993 se empieza a tomar la historia reciente como parte de los contenidos curriculares, no es hasta la derogación de esta ley y la sanción de la Ley Nacional de Educación ( $\left.n^{\circ} 26.206\right)$ en 2006 que Malvinas comienza a ocupar un rol trascendental en la agenda curricular impulsada desde el gobierno. A su vez, esta misma ley coincide con la modificación en la concepción de los materiales pedagógicos-didácticos, cuyo planeamiento, producción y distribución había sido relegado a las empresas editoriales durante los años 90. De esta manera, parecerían registrarse cambios significativos tanto en las formas de circulación y contenidos del discurso pedagógico y, en específico, en el formato y constitución de los libros de texto.

\section{La institución escolar y el libro de texto: el caso de Malvinas}

Como bien han demostrado los estudios etnográficos de las últimas décadas, lo que sucede materialmente enlas escuelas trasciende la mera reproducción de contenido verticalista. Esto es, no solo se encuentran los discursos oficiales o legitimados, sino también otros discursos y visiones que repiensan, cuestionan o validan e incluso ponen a prueba a la hegemonía discursiva. Tomando esto en consideración, afirmamos que la formación de un sentir popular - como la causa Malvinas - excede la influencia monolítica de la institución escolar y que, de hecho, esta concepción reduccionista emplaza a los sujetos activos de la comunidad educativa - directivos, docentes, alumnos e incluso padres- a roles pasivos o meramente reproduccionistas de las lógicas o voluntades políticas de turno.

No obstante, como bien marcan distintos autores en lo que respecta a Malvinas esto no supone soslayar el rol significativo que ha tenido la escuela en la integración de la soberanía insular de Malvinas a la identidad nacional (Escudé 1987 y 1990; Marí, Saab y Suárez, 2000; Romero, 2004; García, 2009; Santos la Rosa, 2019).

En este sentido, debemos tener en consideración que la propia gestación del ser nacional excede los contenidos curriculares específicos y permea toda la 
institución escolar. Para ello es necesario referirnos a la cultura escolar en tanto que esquemas, normas y tradiciones que no siempre están escritas y que abarcan todo: desde la dinámica en las aulas hasta los sentires y los lugares ocupados por cada uno de sus protagonistas (Deal y Peterson, 2009 en Elías, 2015). Siguiendo a Elías, la cultura de la escuela está compuesta por:

Elementos implícitos (...) tales como valores y normas, que se manifiestan a través de artefactos culturales como mitos, héroes y heroínas, y por procedimientos. Estos tres niveles, si bien diferentes, están interrelacionados en la medida en que unos influyen y se expresan en los otros. (Elías, 2015:294)

Por lo tanto, es necesario destacar que estos artefactos son ante todo composiciones en tanto que implican una selección y puesta en relación de algunos elementos de la historia. Construir una mitología, como lo es el ser nacional, supone una operación de recorte de determinados personajes de la historia en detrimento de otros; a su vez, manifiesta la edificación de un imaginario colectivo a partir de determinadas reglas y normas que, aunque intentan naturalizarse, nunca son azarosas y obedecen a un sentido específico e interpretación del pasado que intenta imponerse como unívoca y natural.

En este sentido, los textos escolares han ocupado un lugar privilegiado en la legitimación del ser nacional y los sentidos de la historia argentina. Sirva de ejemplo las representaciones sobre los derechos territoriales sobre las Islas en los manuales escolares de primera mitad del siglo XX. Como señalan distintos autores (Romero, 2004; García, 2009; Santos la Rosa, 2019), a grandes rasgos se puede destacar la preminencia de los derechos territoriales que aparecen configurados en estos materiales pedagógicos como incuestionables e insoslayables. En palabras de Romero estos argumentos:

Parten de una premisa que en ningún momento es puesta en duda, ni sometida a prueba alguna: los derechos de la Argentina sobre las Islas son obvios e indiscutibles. A la hora de exponer los conflictos, concurren cuatro características del discurso de la nacionalidad: la preeminencia del criterio territorial; la confusión entre la función de los derechos territoriales en los estados dinásticos y patrimoniales y en los modernos estados nacionales; la incongruencia entre el relato de los acontecimientos anteriores a 1810 y los derechos incontrastables que España tendría sobre las islas; finalmente, la potencialidad autoritaria de los discursos de la reivindicación territorial, que un verdadero argentino no puede discutir. (Romero, 2004:70)

En consonancia con Romero, La Rosa destaca que estos argumentos se encontraban presentes ya en los primeros antecesores del género manual como en el Compendio de Historia Argentina, para el uso de las escuelas y colegios de la República (1833) de Nicanor Larraín. Desde este siglo aparece un argumento que será vertebrador en el reclamo de soberanía sobre las islas: el reconocimiento de todos los territorios que antes formaban parte del dominio español como automáticamente transferibles al territorio de los nuevos estados independientes (lo que en derecho se conoce como utti possidetis iure).

A su vez, el estudio cualitativo realizado por Marí, Saab y Suárez (2000) pone de relieve el impacto que estos discursos han tenido en la percepción de la identidad nacional. Los autores abordan un estudio de la Enseñanza de Malvinas y el sentir nacional en las escuelas tomando como punto de partida testimonios orales de entrevistas realizadas a cincuenta habitantes de la Capital Federal y el conurbano. Como indican en su trabajo, su interés se centra en dar cuenta de 
la vivencia de personas comunes, es decir, de sujetos que no hayan intervenido directamente en la guerra como militares o excombatientes. Si bien no atribuyen la gestación del espíritu nacional sólo a la escuela, es destacable la vigencia de algunos relatos que nos remiten a las producciones escolares como la frase icónica “iLas Malvinas son y serán argentinas!”.

Si bien estos estudios son válidos y relevantes para analizar cómo fue la integración de Malvinas a la edificación del ser nacional; necesariamente surge la pregunta de si el rol que ocupan hoy en día los manuales y libros de texto es exactamente el mismo o, incluso, si aún merece la pena reparar sobre ellos. Para ello, no hay que desdeñar la inminente revolución tecnológica que atraviesa nuestras vidas y las distintas intersecciones de ella: el ocio, el trabajo, la educación, etc. Las aulas de la escuela secundaria no están exentas de la transformación tecnológica, de hecho, cada vez son más los proyectos que apuntan a incluir a las nuevas tecnologías en el aula.

Sin embargo, las realidades tan diversas y heterogéneas de nuestro país ponen en suspenso algunas ideas del sentido común como aquella que piensa que los libros en formato físico ya no tienen peso en las aulas. Como han demostrado diversos autores, el uso del libro de texto mantiene vigencia en las aulas no solo por cuestiones contextuales -por ejemplo, las limitaciones de accesibilidad tecnológica frente a la existencia de bibliotecas escolares en casi todas las instituciones-, sino también por relaciones con el propio trabajo docente facilita la organización de los contenidos, sugiere temas para trabajar, ayuda a la planificación de las clases, etc.- (Negrin, 2009).

No obstante, nuestro interés en los libros de texto no radica meramente en el uso explícito que se haga de ellos o no en el aula. De hecho, sería un análisis reduccionista abstraer las ideas circundantes de los manuales y libros de texto como expresión de las ideas que se expresan en el aula; ya que en ese caso desestimaríamos el rol activo del docente -que muchas veces realiza tareas de selección y corrección de los manuales y libros de texto, apostando en la mayoría de los casos a un trabajo selectivo con ellos a manera de dossier-o de los mismos alumnos como sujetos políticos.

En este trabajo, los libros de texto nos interesan en primer lugar y fundamentalmente en tanto que actores institucionales -con normas, reglas y dispositivos determinados- cuyas voces vehiculizan y legitiman, en la mayoría de los casos, las ideas y conceptos de la memoria fuertes frente a otras memorias débiles (Traverso, 2010). En el complejo entramado de actores e instituciones que tienen lugar en la cultura escolar, los libros de texto continúan siendo una voz autorizada que se vincula con el Estado mismo -aun siendo de editoriales privadas -, a través de los diseños curriculares esbozados por la Provincia.

En este sentido, son uno de los materiales predilectos a la hora de significar la historia en las escuelas, legitimarla y orientar la práctica como cualquier discurso social (Angenot, 2012). El caso particular de la Guerra de Malvinas, como hemos visto, resulta más interesante que cualquier otro dado que es un caso en el que la memoria oficial aún no ha sido cristalizada y es objeto de disputas a lo largo del tiempo que hacen que la Guerra se resignifique de distintas maneras y, por extensión, las valoraciones de sus actores y de los reclamos a futuro. Por ende, el relato de la Guerra que se hace en los libros de texto y materiales pedagógicos es parte de una contienda simbólica mucho más amplia y en curso. 


\section{Los cambios en la enseñanza de Malvinas y los libros de texto después de la LEN}

Antes de proceder al análisis de corpus propiamente dicho, resulta conveniente retomar algunos puntos relevantes para la contextualización del estudio de los libros de texto del período 2006 a la actualidad. La sanción de la LEN presupone al menos dos consecuencias fundamentales para nuestro estudio: una relacionada en específico con Malvinas como contenido transversal para la Educación Primaria y la Educación Secundaria, ${ }^{4}$ otra en general con las modificaciones en el circuito editorial de producción y distribución de material pedagógico-didáctico y el rol del Estado.

Respecto al primer punto, resulta significativo algunas orientaciones del gobierno en relación a la Guerra. Por ejemplo, el entonces ministro de Educación, Ciencia y Tecnología de la Nación -Daniel Filmus- resaltó la centralidad de los combatientes en la injerencia sobre la enseñanza de Malvinas. Así es que en el acto conmemorativo del 2 de abril destacó "Me parece que el trabajo que hacen los ex combatientes para que la memoria esté presente día a día es un trabajo fundamental, no existe un país sin memoria. Si uno no sabe de dónde viene, no sabe a dónde va" ("El eje en los que pusieron el cuerpo" 2007).

De igual manera, recibió a los combatientes para ser consultados acerca de la conmemoración de esta fecha:

\footnotetext{
Cuando fue la guerra de Malvinas todos sabíamos que eran nuestras porque lo habíamos aprendido en la escuela. Ahora tenemos el desafío de cumplir con lo que dice la Ley de Educación Nacional e incorporar la memoria de lo que ocurrió en Malvinas en los contenidos educativos. Una tarea que no es para un día, sino que iniciamos hoy para que esté presente para siempre en el sistema educativo argentino. (De Amézola y otros, 2007:70)
}

Estas declaraciones, en conjunto con los programas impulsados desde el Ministerio -con especial énfasis en el programa Educación y Memoriapresentan un panorama en el que Malvinas en general comienza a ocupar un lugar trascendental en la Educación y, por lo tanto, el estudio de los materiales pedagógicos-didácticos constituye un productivo punto de partida para acercarse a estas representaciones del pasado reciente.

En consonancia con esto último, también se modifica el rol del Estado en la producción y distribución de libros de texto. Desde los años 90 hasta principios del nuevo milenio, el Estado se había mantenido al margen de estas tareas, otorgando mayor jerarquía a las empresas editoriales. De esta manera, la incipiente independencia del texto escolar hace que durante esta época se consolide como un género particular con un conjunto de normas y reglas propias que terminan por establecer ciertos "modos de decir pedagógicos" (Tosi, 2018), ligados al polo comercial. ${ }^{5}$ La organización del libro de texto empieza a contar con una estructura marcada por la división en áreas, unidades temáticas y una organización de secuencias expositivas con menor jerarquía que en los modelos anteriores, dado que empiezan a cobrar mayor relevancia las actividades. A su vez, también se insertan discursos de otras áreas tales como el discurso mediático y de las nuevas tecnologías.

A partir dela LEN el Estado comienza a participar en actividades de coordinación, orientación y capacitación de las editoriales, instituciones que se 
habían fortalecido y consolidado durante los 90. Por consiguiente, asistimos a un escenario editorial algo más complejo que en los 90, dado que ahora las editoriales se han consolidado como actores fundamentales en la producción de libros de texto luego de más de una década de predominio y también se han conformado distintas improntas identitarias dentro de las diversas propuestas editoriales; pero, no obstante, el Estado comienza a jugar un rol de supervisión y asistencia que contrasta con la política anterior que dejaba todo en manos de los actores privados.

Como intentaremos demostrar las estrategias discursivas no están únicamente orientadas a la enseñanza sino también a la argumentación y legitimación de una lectura de la Guerra como lectura válida y unívoca.Dado que nos interesan las articulaciones entre pasado reciente, memoria e Historia, hemos seleccionado libros de texto de Historia de 5to año ${ }^{6}$ ya que en este se ubica la Guerra de Malvinas como contenido específico, a partir del último diseño curricular provincial modificado por última vez en el 2011, ya que abarca la segunda mitad del siglo XX.

\section{Las páginas donde se escribe la historia: análisis de corpus}

A fin de proporcionar una lectura sistematizada del trabajo, presentamos los análisis discursivos en secciones organizadas a partir de puntos nodales que persisten en los distintos libros. Estos nodos temáticos son objeto de reescrituras, problematizaciones y persistencias que manifiestan la productividad del carácter polémico y abierto de la Guerra de Malvinas.

Siguiendo a Angenot, estos temas constituyen visiones de mundo, en tanto que todo debate presupone no solo el acuerdo entre las dos partes de la existencia de determinado tema sino también la relevancia implícita que posee para justificar la confrontación de distintos puntos de vista. En ese sentido, trabajar con documentos de alguna forma oficiales -en tanto guardan relación con las resoluciones educativas estatales-, supone una vía de entrada a las construcciones de memoria divergentes que se insertan en el debate por la historia reciente.

Si bien esta es una sistematización sugerida para presentar una lectura organizada, lo cierto es que al tratarse de temas interrelacionados constantemente resulta inevitable la mención o referencia entre uno y otro.

\section{1. ¿A quién pertenece la guerra? Agentividad y pasividad como construcciones representacionales}

El término representación es plausible de ser entendida en su sentido teatral: cómo se distribuyen los papeles y las acciones. Este es uno de los pilares fundamentales que desencadenan las distintas visiones en el imaginario colectivo sobre la Guerra de Malvinas. Por ende, constituyen preguntas fundamentales las de quiénes estuvieron involucrados en la guerra, quiénes oficiaron como agentes -esto es, con voluntad y decisión en las acciones- y quienes tuvieron un papel pasivo y cómo se construyen isotopías de significado en torno a cada una de las figuras involucradas. 
Sin lugar a dudas, los conceptos de agentividad y pasividad resulta vertebradores de estas representaciones, ya que responden a las preguntas ¿quiénes tuvieron decisión y acción sobre la Guerra y quiénes no? Como veremos, estas figuraciones se materializan en recursos retóricos y discursivos propios como las elecciones léxicas y la pasivización y también a nivel del discurso pedagógico, mediante la incorporación de recursos propios del discurso pedagógico.

\subsection{La figura de la Junta Militar y Galtieri}

La Guerra de Malvinas es representada en la mayoría de los libros de texto como un episodio más de la dictadura militar. Por lo tanto, la presencia de la dictadura concentrará la mayor parte de la agentividad en torno a la Guerra.

Las representaciones de este actor oscilan en un rasgo de más a menos personalización: en un extremo nos encontramos con referencias más colectivas y abstractas tanto como "gobierno", "Junta Militar" e incluso "dictadura" para referirse al gobierno de facto; por otro lado, con un rasgo de mayor personalización aparece la figura de Leopoldo Galtieri marcada sólo por un sustantivo propio, el de su apellido.

Un ejemplo es el análisis de las marcas topográficas de los textos. Es propio del género pedagógico / didáctico incluir estrategias de facilitamiento (Tosi, 2018) para orientar la lectura y la extracción de las “ideas principales”. Esta orientación es una de las manifestaciones más claras desde la puesta en funcionamiento del discurso de cómo debe leerse la información que allí se está brindando. En este sentido, también vehiculizan significancias y están orientadas hacia las representaciones generales de la Guerra. En los libros de textos la marcación es unánime: se resaltan principalmente los nombres de los miembros de la Junta Militar (Binogne, Viola, Galtieri) y las Islas Malvinas.

En efecto, en la mayoría de los manuales la agentividad de la guerra se encuentra circunscripta a la acción de la Junta Militar presidida por Galtieri. No solo en las representaciones sino también en las implicancias semánticas de las decisiones léxicas: constituyen los sujetos semánticos de la mayoría de los verbos que proyectan un sujeto agentivo, es decir, un sujeto que provoca conscientemente la acción que el verbo desencadena. Los verbos marcados en negrita por nosotros en los fragmentos seleccionados constituyen un muestrario de esto: "En medio de este clima, el gobierno tomó la decisión de recuperar las Islas Malvinas (...). La decisión obedecía a problemas internos de las Fuerzas Armadas, pero fue apoyada por una parte de la población civil" (Acuña y otros, 2007. La cursiva es nuestra). Más adelante se dirá: "Dispuestas a restablecer su autoridad, y con el objetivo de aglutinar a la sociedad, las fuerzas armadas decidieron jugar una carta que les permitiría ganar legitimidad social: la recuperación de las Islas Malvinas (...)” (Tato y otros, 2011. La cursiva es nuestra). Todos los libros de texto aceptan sin restricciones la idea de las Fuerzas Armadas como idearios únicos de un plan de Guerra que, más que recuperar las Islas, apuntaba a salvar a la dictadura y como los responsables de la pérdida de la Guerra, debido a lecturas y decisiones erróneas.

No obstante, la decisión de ir a la Guerra también tiene distintos rasgos de personalización en los libros. Mientras que en algunos se colectiviza esta responsabilidad -en la figura de las "fuerzas armadas" o "gobierno militar"-; en otros libros como los de Ediciones Maipue esto se personaliza hasta tal 
punto que se le otorga a Galtieri calificaciones cuasi caricaturescas y ególatras. Es él quien "pensó que si recuperaba una parte del territorio argentino" luego se consagraría como "héroe nacional" (Egger-Brass y Gallego, 2011). De esta manera, se construye un enfoque de la historia más centrado en las figuras y no en los procesos históricos multi-factóricos.

Las distintas propuestas editoriales también varían en la construcción que hacen del escenario que da lugar a la aparición de la Guerra. Mientras algunas propuestas mencionan los conflictos hacia el interior de las Fuerzas Armadas, otras solo se circunscriben a los hechos inmediatos como el fracaso del plan económico de Alemann. Tal es el caso de la propuesta de Estrada, que sintetiza: "Ante el fracaso a corto plazo del plan económico de Alemann, los militares plantearon una invasión a las Islas Malvinas" (Tato y otros, 2011).7

La subordinación causal, expresa en este caso, se mantiene con variantes en los otros textos: ante una situación que no tiene control para la dictadura, se decide ir a la Guerra como forma de solucionar ese conflicto. En los textos se refuerza esta disposición en relación de causa - consecuencia reforzada en el siguiente ejemplo por la construcción de una subordinada causal: en tanto que falla el modelo económico de la dictadura, se hace necesario ir a la Guerra.

Ahora bien, siguiendo este razonamiento se desprende un presupuesto: ir a la Guerra implicaría el consenso social que la Junta necesitaba para legitimarse el poder. Sin dudas, aquí se introduce uno de los elementos más polémicos.

Si bien en este trabajo nos circunscribiremos a la representación del conflicto bélico en sí, basta decir algunas cuestiones en torno a la construcción del pueblo como parte de la Historia. A grandes rasgos se establece una clara distinción entre nacionalismo acrítico y causa popular que desentraña, a su vez, concepciones sobre la agentividad del pueblo en sí mismo. La mayoría de las propuestas editoriales circunscriben el nacionalismo a algo espontáneo y acrítico:

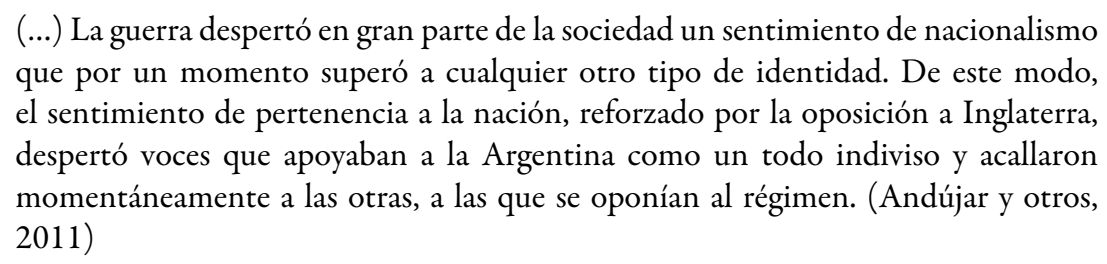
que por un momento superó a cualquier otro tipo de identidad. De este modo, el sentimiento de pertenencia a la nación, reforzado por la oposición a Inglaterra, despertó voces que apoyaban a la Argentina como un todo indiviso y acallaron momentáneamente a las otras, a las que se oponían al régimen. (Andújar y otros, 2011)

En estos textos la adhesión a la Guerra aparece simplifica y conduce a extender el papel de la sociedad no solo al rol pasivo provocado por el frenetismo del despertar del nacionalismo, ${ }^{8}$ también se extiende la culpabilidad por la perpetuación del poder de la Junta, dado que el pueblo es el que ocupa el lugar de censurar y acallar a los disidentes.

En una minoría del corpus -Edición 2012 de Santillana y edición de Maipuese intenta construir, al menos someramente, las implicancias de Malvinas en tanto que causa nacional. ${ }^{9}$

\subsection{Los combatientes argentinos}

Los combatientes argentinos son los otros grandes protagonistas de la Guerra de Malvinas, en tanto que junto con la Junta Militar son los que aparecen con mayor frecuencia en el relato. Ahora bien, si rastreábamos cierto consenso entre 
los libros en relación a la representación de la Junta Militar realizada, en el caso de los combatientes las suposiciones se complejizan un poco más. La existencia de representaciones divergentes entre sí no hace más que acentuar el carácter polémico en torno a la figura del combatiente que se muestra lejos de ser un debate clausurado.

A fin de sistematizar los datos, realizamos un cuadro comparativo que muestra los sintagmas nominales proferidos para referirse a los combatientes de Malvinas. Para realizarlo no solo atendimos a la cantidad de veces que aparece una palabra inserta sino también en qué jerarquía discursiva entra, esto es, si se trata del nivel textual o paratextual -epígrafe, documentos, actividades-. En este apartado, nos centraremos en el análisis de los subjetivemas ${ }^{10}$ presentes en la dimensión textual.

Tabla 1.

\begin{tabular}{|l|l|l|l|}
\hline Sintagma & Frecuencia total de aparición & Manuales en los que apareció & Nivel \\
\hline Jóvenes & 4 & $\begin{array}{l}\text { Saberes Clave 2012 1 DgdCyE 2011 1 Maipue V } \\
2011\end{array}$ & $\begin{array}{l}\text { Textual Textual } \\
\text { Textual }\end{array}$ \\
\hline Soldados & 4 & $\begin{array}{l}\text { DGDCyE 2007 1 Saberes Clave 2011 1 Maipue VI } \\
\text { 2011 Maipue V 2011 }\end{array}$ & $\begin{array}{l}\text { Paratextual } \\
\text { Paratextual } \\
\text { Paratextual Textual }\end{array}$ \\
\hline Tropas argentinas & 3 & $\begin{array}{l}\text { Saberes Clave 2011 1 Saberes Clave 2012 2 DgdCyE } \\
20071\end{array}$ & $\begin{array}{l}\text { Textual Textual } \\
\text { Textual }\end{array}$ \\
\hline Conscriptos & 3 & $\begin{array}{l}\text { Saberes Clave 2012 1 Saberes Clave 2011 1 Maipue } \\
\text { V 2011 }\end{array}$ & $\begin{array}{l}\text { Paratextual Textual } \\
\text { Textual }\end{array}$ \\
\hline Hombres & Huellas 2011 1 Saberes Clave 2012 1 & Textual Paratextual \\
\hline Argentinos & 2 & Saberes Clave 2012 1 DgdCyE 2011 1 & Textual Textual \\
\hline Chicos & 2 & Saberes Clave 2011 & Textual \\
\hline Colimbas & 1 & Saberes Clave 2012 1 & Paratextual \\
\hline Efectivos & 1 & Saberes Clave 2012 & Paratextual \\
\hline Víctimas & 1 & Maipue V 2011 & Textual \\
\hline
\end{tabular}

En su ya clásico libro De chicos a veteranos, Rosana Guber (2004:11) resume en tres las representaciones de los conscriptos para la sociedad: "como protagonistas no entrenados del evento bélico, como retrato de patriotismo de los argentinos y como víctimas del autoritarismo del régimen".

En los libros de texto se observa una sinécdoque semántica a partir de la que se equipara a todos los combatientes de las Fuerzas Armadas - pertenecientes al Ejército, la Armada y la Fuerza aérea - únicamente con los soldados conscriptos. No obstante, según los datos del Ministerio de Defensa de la Nación, ${ }^{11}$ la mayoría de los combatientes provenían de la Armada, seguidos por el Ejército, la fuerza Aérea y con menor presencia la Prefectura y Gendarmería.

A su vez, los conscriptos solo son representados con dos de las tres tendencias que menciona Guber. Efectivamente, el patriotismo de los argentinos es una representación totalmente ausente en la construcción semántica de los combatientes y solo aparece en las formas del nacionalismo acrítico - y en menor medida, la causa nacional -.

No resulta casual que en las elecciones léxicas predomine "jóvenes" tanto como adjetivo calificativo ("jóvenes soldados conscriptos" (Eggers-Brass y Gallego, 2011)) como sustantivo pleno ("jóvenes que cumplían con el servicio militar obligatorio" (Acuña y otros, 2007)). La juventud se resalta en un único sentido isotópico en tanto que debilidad, inexperiencia y carencia. Lo encontramos en el manual de DGCYE: "Murieron alrededor de 600 argentinos, en su mayoría jóvenes que cumplían con el servicio militar obligatorio” Acuña y otros, 2007) 
y en una forma de mayor condescendencia como "chicos": “(...) Chicos de 18 y 19 años que se encontraban haciendo el servicio militar obligatorio y no tenían la preparación necesaria"; "Ahora quedaba en evidencia que los jóvenes conscriptos habían sido enviados a combatir en una guerra sin preparación militar necesaria, sin los armamentos adecuados ni elementos básicos como abrigo y alimento" (Andújar y otros, 2011)

En este sentido, en las representaciones de los libros de texto conviven las dos tendencias: la inexperiencia y falta de preparación junto con el rol de víctimas de la dictadura. ${ }^{12}$ Esto no solo se manifiesta en las elecciones léxicas con carga valorativa -tales como jóvenes o chicos- sino también en las construcciones oracionales de las que forman parte. En consecuencia, los combatientes no solo son disminuidos en su agentividad por ser considerados jóvenes inexpertos sino también por ser pacientes o sujetos pasivos víctimas de las acciones de un ente externo.

A partir de la jerarquía semántica de los casos de la lengua, donde el nominativo ocupa la posición de mayor agencia mientras el acusativo ocupa la de menor agencia, los combatientes suelen ocupar el lugar menos agentivo (como objetos que "habían sido enviados", por ejemplo).

Lo mismo sucede con otras elecciones léxicas como el caso de "tropas argentinas". Como hemos resaltado en antiguos trabajos (Bottazzi, 2019), la utilización de tropas argentinas coincide con una reducción agentiva de los sujetos. El sustantivo colectivo en lugar del sustantivo individual pluralizado, propicia el rasgo de mayor indefinición que sumado a las posiciones sintácticas y sus reminiscencias semánticas, contribuyen a una figuración de las tropas como elementos pasivos o subsidiarios del relato.

Observamos cómo "tropas argentinas" se inserta como complemento directo - posición sintáctica donde rige el caso acusativo - en las oraciones de las que forma parte: "La ONU (...) ordenó el retiro de las tropas argentinas" (Andújar y otros, 2012). O bien, cuando logra tener un enfoque agentivo se debe a acciones como la rendición.

Otro aspecto a revisar refiere a los procesos de selección de la historia. Es decir, debido a las limitaciones de extensión impuestas por las editoriales y el género mismo, el relato de la Guerra - así como cualquier otro relato en los libros de texto - constituye un mero recorte o selección de episodios que se juzgan claves y merecen aparecer.

La efectividad del discurso pedagógico radica en qué tan efectivas sean las maniobras de ocultamiento de esa selección. En otras palabras, el discurso pedagógico intenta que esa operación selectiva devenga en un relato natural y neutro de la historia. Por ende, un punto esencial a destacar son los sucesos que se relatan y cuáles no aparecen, en tanto que son selecciones que habilitan la construcción de una historia legítima.

De esta manera, en su mayoría los libros de texto no hacen una reconstrucción de la Guerra en sí misma. Solo refieren al desembarco del 2 de abril, la descripción de los combatientes argentinos, la superioridad británica y la rendición. Como excepción, solo los libros de Maipue y la segunda edición de Santillana se refieren al hundimiento del Crucero General Belgrano, un episodio clave para comprender el desarrollo de la contienda bélica de Malvinas. Mientras que Santillana reduce los episodios de la Guerra a una especie de recuento de 
efemérides y bajas ("el 2 de mayo un submarino inglés bombardeó al crucero General Belgrano (...) dejando como saldo 300 muertos”, Andújar y otros, 2012), Maipue habilita la problematización de este episodio mencionando que no formaba parte de la zona de exclusión inglesa. Si bien el término aparece entrecomillado, en tanto que se marca la terminología externa al discurso del libro de texto, no se explicita su significado y se da por hecho que los estudiantes lo saben.

Si bien el hecho es el mismo, la inclusión mediante distintas estrategias discursivas hace que se habiliten al menos dos orientaciones semánticas: en el caso de la editorial Santillana, la inclusión del hundimiento del General Belgrano abona a la teoría construida de que se trataba de una guerra desigual y perdida desde el inicio. En cambio, el mismo episodio en Maipue - a partir de la inclusión del término "zona de exclusión" - ayuda a problematizar la figura del enemigo y la controversia en torno a su actuación en la no-zona de combate.

Además, resulta necesario incluir que en las ediciones de Maipue también se incluye el hundimiento del buque inglés Sheffield, un hecho que es obviado en el resto de las propuestas editoriales. La inclusión de este hecho podría contrarrestar a la representación de los combatientes como víctimas o sujetos reducidos en su agentividad. Por ello, el autor-locutor del texto juzga necesaria la inclusión de una adversativa que permita introducir un segundo enunciado con una orientación semántica coherente a la de todo el relato: "pero la flota inglesa dominaba el mar" (Eggers-Brass y Gallego, 2011).

Es este encauzamiento semántico hacia la representación dominante el que le permite a los libros de Maipue hacer mención a los combatientes caídos en calidad de "víctimas de la dictadura". ${ }^{13}$ A su vez, esta edición en particular hace una focalización extra sobre los combatientes sobrevivientes por medio de construcciones que, nuevamente, apelan a lo emocional. En ese sentido, se menciona que "casi un millar (...) estaban mutilados y heridos". Por otro lado, la condición de víctima en Maipue no es explicita solo por la representación de combatientes inexpertos enviados a morir, sino también porque es la única propuesta editorial que hace mención a la "violación de los derechos humanos hacia los jóvenes combatientes". Esto hace que en algún punto los conscriptos sean equiparados a las víctimas del terrorismo de Estado, como bien se resume en la frase "Ellos y los cientos de ex combatientes que se suicidaron se convirtieron en otras víctimas de la dictadura" (Idem). (La cursiva es nuestra).

\subsection{El contendiente británico y las estructuras comparativas como construcciones argumentativas}

Contrario a la prolífica aparición de la Junta Militar y los combatientes en los libros, el contendiente de la Argentina en la Guerra aparece reducido como tal y su manifestación es bastante irregular. De hecho, en algunos libros figura únicamente en una oración como es el caso de la edición 2011 de Saberes Clave: "Entre el 20 y 21 de mayo las tropas inglesas finalmente desembarcaron en las islas, lo que hizo inminente la derrota argentina" (Andújar y otros, 2011). El solo desembarco de las tropas garantiza la derrota enfatizada por la valorización a partir del subjetivema "inminente". 
Las restantes representaciones de los otros manuales, convergen en líneas generales con las de Saberes Clave 2011. Así, el contendiente aparece reducido en el cuerpo textual y ausente en el plano paratextual. Principalmente, funciona como elemento de una construcción comparativa que refuerza la asimetría y desventaja de las tropas argentinas frente a las británicas, por medio de subjetivemas de corte superlativo que exaltan las condiciones de las tropas británicas (las negritas de los ejemplos son nuestras): "Los británicos contaban con un armamento tecnológicamente superior y con combatientes mejor entrenados que las tropas argentinas" (Acuña y otros, 2007; las cursivas son nuestras). "En realidad, en el plano militar, el poderio y la organización británicos superaron el caótico e improvisado dispositivo militar argentino" (Andújar y otros, 2012; las cursivas son nuestras). "Con el pasar de los días, fue evidente que la superioridad británica era aplastante” (Tato y otros, 2011; la cursiva es nuestra).

Esta visión algo simplista abona a la idea de una guerra absurda en tanto que, incluso antes de comenzar, estaba condenada al fracaso de la empresa argentina. Aunque implícita, en los fragmentos se evidencia la superioridad británica en al menos dos aspectos- armamentístico/tecnológico y organizativos - que merecen ser problematizados. En el manual 2012 de Saberes Clave se enfatiza, por contraste, que la mayor debilidad argentina fue en el ámbito organizativo estratégico. Por otro lado, en el resto de las representaciones es la preparación tecnológica y el entrenamiento los que son marcados como puntos débiles que llevan a la derrota.

El hecho de que esta diferencia aparezca diluida en los textos, constituye un problema no solo porque no clarifica los motivos de la derrota argentina; sino también porque, a grandes rasgos, marginaliza la idea de la Guerra de Malvinas como un conflicto bélico entre Argentina y Gran Bretaña. En efecto, la dimensión internacional y geopolítica -así como la disputa internacional en torno a territorios de importancia estratégica como las Islas Malvinas- aparece diluida y, en la mayoría de los casos, ausente en los libros de texto analizados.

Solo las ediciones de Maipue traen a colación el rol del gobierno británico- y en específico, de Margaret Thatcher- en la Guerra de Malvinas. Es que mientras en las otras propuestas editoriales, la aparición de los británicos como contendientes se reduce a la superioridad de las tropas combatientes y ni siquiera se menciona a la primera ministra británica; Maipue menciona el rol activo de la dirigente: "Convenció a los ingleses para ir a la guerra; bajo el argumento que se trató de un acto de invasión realizado por una dictadura militar acusada de violar los derechos humanos, y por lo tanto, que no merecía ningún tipo de consideración ni acuerdo diplomático" (Eggers-Brass y Gallego, 2011).

En este sentido, Maipue plantea un interesante punto de debate que se condensa en una estrategia polifónica. Con la introducción del sintagma "bajo el argumento" se introduce un enunciado del que el locutor se distancia y por ello solo se lo atribuye a la primera ministra británica. El "por lo tanto" es la deducción que de este segundo enunciado se desprende, pero de la que el locutor se distancia mediante la selección léxica con carga peyorativa ("no merecía") y la cuantificación negativa ("ningún tipo de consideración ni acuerdo diplomático"). De esta forma, el rol de Thatcher no es solo incluido, sino que también problematizado mediante estrategias microdiscursivas particulares. 


\subsection{Las consecuencias de la Guerra}

$\mathrm{Si}$ atendemos a los rasgos paratextuales, encontraremos una correspondencia semántica entre el discurso y las imágenes. La imagen resulta un elemento fundamental de los libros de texto y, en específico, de los libros de Historia. Esto se debe a que la organización topológica de la página se centra en la secuencia textual más que en ninguna otra y existe escasos recursos paratextuales. En ese sentido, las imágenes proceden como una especie de "resúmenes semánticos" del discurso contenido en el texto propiamente dicho.

A grandes rasgos, en las imágenes encontramos una huella semántica de las representaciones de la Guerra que se manifiestan en el texto: en cuanto a sus grandes protagonistas -Galtieri y los soldados conscriptos- y sus roles -el hacedor y las victimas-.

La imagen de Galtieri aparece en dos propuestas editoriales: la edición de Estrada y ambas ediciones de Santillana. En estas imágenes se observa una representación triunfalista del entonces presidente de facto. En el libro de Estrada encabeza con una sonrisa una conferencia de prensa, debajo se titula "Galtieri se dirige a la prensa en Comodoro Rivadavia, el 23 de abril de 1982" (Tato y otros, 2011). En lo que respecta a los combatientes argentinos, las imágenes refuerzan las orientaciones semánticas del texto. Todos los combatientes que aparecen allí son soldados con la particularidad de que no aparecen imágenes en combate, sino fundamentalmente imágenes de la rendición o la toma como prisioneros reforzados por los epígrafes.

Como puede desprenderse del análisis hecho hasta aquí, el principal resultado de la Guerra destacado por los libros de texto es la pérdida de legitimidad del régimen autoritario y el consecuente "fin de la dictadura". En este punto es preciso atender el lugar destacado que ocupan las bajas argentinas. Excepto la edición de Estrada, todos los libros de texto hacen mención a las bajas numéricas argentinas y solo algunos a las bajas inglesas, lo que evidencia la asimetría en la representación de ambos contendientes: "La intervención militar en Malvinas (que costó la vida de alrededor de 700 argentinos y 300 británicos, además de miles de heridos) concluyó en un estrepitoso fracaso (...)" (Andújar y otros, 2012); "Murieron alrededor de 600 argentinos, en su mayoría jóvenes que cumplían con el servicio militar obligatorio" (Acuña y otros, 2007); "El saldo del conflicto fue un gran número de prisioneros de guerra, 730 muertos y miles de heridos de gravedad" (Andújar y otros, 2011); o "Habían muerto más de 700 personas (la mayoría jóvenes soldados conscriptos7) y casi un millar más estaban mutilados y heridos. Ellos y los cientos de ex combatientes que se suicidaron se convirtieron en otras víctimas de la dictadura" (Eggers-Brass y Gallego, 2011).

En primer lugar, cabe destacar la orientación semántica de las cifras numéricas en el contexto discursivo dado que es una apelación a la naturaleza factual de los acontecimientos y, por tanto, un reforzador de la construcción de naturalidad del discurso pedagógico. Si todas las estrategias discursivas se orientan a generar determinada orientación de lectura en el lector, es válido preguntarnos cuáles son los efectos que pretenden generar. En otras palabras, la inclusión de las cifras viene a reforzar la representación vehiculada por los libros en la que la Guerra de Malvinas fue una guerra desigual y absurda desde el principio y cuyas consecuencias eran previsibles. 
Ahora bien, en un análisis para desnaturalizar lo que nos viene dado como objetivo y natural, resulta necesario destacar la falta de consenso entre los distintos textos respecto a las cifras. En algunos casos, existe una diferencia de más de 100 caídos y otro tanto con los heridos (desde "miles" a "millares"). Por otro lado, se eliden otras cuestiones propias del conflicto bélico que problematizarían, en principio, la idea que pareciera sostenerse de una guerra desigual y absurda; tales como el rol de los pilotos y las caracterizaciones del combate terrestre. ${ }^{14}$

A su vez, la construcción de sentido del resultado de la guerra es composicional en tanto que se da no solo por los últimos párrafos, sino principalmente por las selecciones y estrategias discursivas anteriores. La inserción de la cifra de caídos, sin hacer referencia a los caídos del contendiente británico ni al episodio del hundimiento del General Belgrano resulta problemática. Esto se debe a que a simple vista una mera comparación numérica (700 contra 300) no refleja las particularidades del combate y vehiculiza una idea simplista de los resultados. De hecho, en el hundimiento al Belgrano se produce la caída de la mitad de los combatientes argentinos. Sin embargo, sin esta aclaración pertinente, la lectura de la Guerra que se abona es consecuente con una visión simplificada del conflicto.

Finalmente, la mayoría de los relatos de la Guerra de los libros de texto se cierran de manera circular volviendo al tópico del apoyo popular y el rol del pueblo: "El desenlace despojó a Galtieri de la legitimidad que había obtenido durante este breve período" (Andújar y otros, 2011); "La derrota militar fue a la vez inevitable e inesperada" (Andújar y otros, 2012); "Con la rendición quedaba al desnudo la irresponsabilidad y la ineptitud de los altos mandos militares" (Eggers-Brass y Gallego, 2011).

En este sentido, la derrota de la Guerra es representada como un shock que despierta al pueblo del letargo nacionalista en el que estaban sumidos y, por lo tanto, habilita el retorno de la democracia.

\section{Comentarios finales}

Como anunciábamos en la introducción, la construcción de una hegemonía discursiva no es algo dado de una vez y para siempre. Por el contrario, las visiones de mundo que son legitimadas deben ser revalidadas constantemente frente a otras visiones contrahegémonicas que las ponen a prueba. De igual manera, para insertarse en la hegemonía actual, la Guerra de Malvinas tuvo que sufrir una reactualización para ingresar a un esquema social donde ciertos valores - como el nacionalismo y la defensa de la soberanía por todos los medios - son puestos a prueba.

En el recorrido analítico hecho es posible trazar una tendencia sobre las representaciones de la Guerra que es hegemónica y, por ende, prevalente: la Guerra es condenada por ser vista como la búsqueda irresponsable de la Dictadura de una salida a sus problemas internos y externos. De esta manera, se desencadena una visión de la Guerra que es entendida esencialmente como un conflicto entre la sociedad civil -encarnada en el escenario bélico como los combatientes en tanto que soldados conscriptos- y la Junta Militar.

Esta visión propicia ciertas operaciones y enfoques de algunos protagonistas y hechos en detrimento de otros. Así, los protagonistas principales son la Junta Militar y los combatientes son solo los soldados conscriptos. La identidad de los 
conscriptos, conforme al imaginario social persistente, sigue construyéndose a partir de la juventud en tanto que inexperiencia y vulnerabilidad. La construcción que predomina es que la Dictadura ha enviado irresponsablemente a los jóvenes a sacrificar sus vidas para poder mantenerse en el poder y, por ende, algunas representaciones tienden puentes entre la imagen del soldado conscripto y las víctimas de la última dictadura militar.

En contraposición, las alusiones al contendiente son mínimas y utilizadas únicamente como contraste de las dificultades técnicas y estratégicas de las tropas argentinas. En este sentido, se reproducen ideas que hablan de la guerra como una guerra imposible o desigual y que, como hemos mencionado, no son debidamente problematizadas ni contribuyen a la contextualización internacional del conflicto.

En esta representación global, se vuelve compleja la descripción del papel activo del pueblo argentino durante la Guerra. Por ello, en su mayoría se tiende a invisibilizar su participación o reducirla a una cuestión de nacionalismo acrítico y espontáneo surgido de manera fervorosa a partir del anuncio de la Guerra.

Si bien esta representación es la hegemónica, no debe entenderse por ello que en todos los libros de texto se exprese de igual manera. Por el contrario, en el corpus analizado pueden observarse distintas gradaciones. Por ejemplo, si bien todas las propuestas editoriales coinciden en darle a la Guerra el matiz de operación de salvataje de la dictadura, existen debates en las representaciones del rol del pueblo y, en menor medida, de los combatientes argentinos y el contendiente británico.

En cuanto a las estrategias discursivas podemos decir que todas ellas apuntan a una simplificación de la representación de la Guerra en pos de la homogeneización de contenidos. De esta manera, ninguno de los textos habilita la comparación de puntos de vista ni resalta la condición subjetiva de las representaciones del pasado reciente o la tensión propia que existe en la construcción de una memoria de Malvinas.

Sin dudas, este es un aspecto crucial a trabajar no solo en los libros de texto sino en todos los géneros didácticos-pedagógicos. No solo en un aspecto general sobre manejo y competencia en el género académico ${ }^{15}$ sino también particular: la Guerra de Malvinas es un episodio particular de nuestra historia que pone en tensión numerosas variables que hacen a la identidad colectiva y nacional.

\section{Referencias}

Angenot, M. (2012). El discurso social: los limites de lopensabley lo decible. Buenos Aires: Siglo XXI.

Bottazzi, F. (2019). "Los chicos de la guerra” y los chicos y las guerras. Los manuales escolares y la disputa de sentido en la enseñanza de Malvinas. II Jornadas sobre la cuestión de Malvinas, La Plata, Universidad Nacional de La Plata.

Cisilino, J. M.; García Larocca, M. \& Garriga Olmo, S. (2020). "Si quieres saber cómo te fue en la guerra, pregúntale a tu enemigo". Aportes británicos para repensar la guerra de Malvinas. Cuadernos de Marte, 18, 424-456.

De Amézola, G.; Dicroce, C. A., \& Garriga, M. C. (2007). Cuentos de guerra: el conflicto de Malvinas en la escuela. Clio \& asociados. La historia enseñada, 11, 69-88. 
Elias, M. E. (2015). La cultura escolar: aproximación a un concepto complejo. Revista electrónica Educare, 19(2), 285-301.

Escudé, C. (1987). Patología del nacionalismo. El caso argentino. Buenos Aires: Instituto Torcuato Di Tella/ Editorial Tesis.

Escudé, C. (1990). El fracaso del proyecto argentino. Educación e ideología. Buenos Aires: Instituto Torcuato Di Tella/ Editorial Tesis.

García, A. B. (2009). Textos escolares: Las Malvinas y la Antártida para la "Nueva Argentina" de Perón. Antiteses, 2(4), 1033-1058.

Guber, R. (2001). ¿Por qué Malvinas? De la causa nacional a la guerra absurda. Buenos Aires: FCE.

Guber, R. (2004). De chicos a veteranos. Memorias argentinas de la Guerra de Malvinas. Buenos Aires: Antropofagia / IDES.

Guber, R. (2019). Haciendo un problema de investigación naval sobre el conflicto por las Malvinas e islas del Atlántico Sur, 1982. 2das Jornadas sobre la Cuestión Malvinas (1-16), UNLP, La Plata.

Guber, R. (2019). Una guerra implausible. Las ciencias sociales, las humanidades y el lado moralmente probo en los estudios de Malvinas. En AAVV. Dossier|La guerra y posguerra de Malvinas. Aproximaciones a un campo en construcción (1-31). Buenos Aires: Programa Interuniversitario de Historia política.

Marí, C.; Saab, J., \& Suárez, C. (2000). "Tras su manto de neblina,..." las Malvinas como creación escolar. Revista de Teoría y Didáctica de las ciencias sociales, 5, 25-59.

Negrin, M. (2009). Los manuales escolares como objeto de investigación. Educación, Lenguaje y Sociedad, 6, 187-208.

Romero, L. (2004). La Argentina en la escuela: la idea de nación en los textos escolares. Buenos Aires: Siglo XXI.

Santos La Rosa, M. (2019). La construcción histórica de una causa nacional en el ámbito escolar (1870-1945). Clio \& Asociados. La Historia enseñada, 28, 20-32.

Tosi, C. (2018). Escritos para enseñar. Los libros de texto en las aulas. Buenos Aires: Paidós.

Traverso, E. (2007). El pasado: instrucciones de uso. Historia, memoria, politica. Madrid: Marcial Pons/ Ediciones Jurídicas y sociales.

Traverso, E. (2010). Historiar la memoria. Viento sur, 113, 79-83.

\section{Corpus analizado}

Acuña, P.; Bazán, S.; Da Orden, M.; Leoni, D.; Lucchetta, L.; Quiroga, N.; Rodríguez, D.; Sánchez M. y Velázquez, G. (2007). Ciencias sociales 3 ES. Buenos Aires: Dirección General de Cultura y Educación de la provincia de Buenos Aires.

Andújar, A.; Giordano, V.; Grammático, K.; Guevara, G.; Morichetti, M.; Scirica, E.; Vissani, G.; Visanni, V. y Wahren, C. (2011). Historia. Argentina y el mundo. La segunda mitad del siglo XX. Serie: Saberes clave. Buenos Aires: Santillana.

Andújar, A.; Grammático, K.; Morichetti, M.; Pita, V.; Scirica, E. y Vissani, V. (2012). Historia argentina en el contexto latinoamericano y mundial (1850 hasta nuestros días). Serie: Saberes clave. Buenos Aires: Santillana.

Eggers-Brass M. T. (2012). Historia VI. Historia reciente en la Argentina. Buenos Aires: Maipue.

Eggers-Brass, M. T. y Gallego M. (2011). Historia V. Argentina, America y el mundo en la segunda mitad del siglo XX. Buenos Aires: Maipue. 
Tato, M. I.; Bubello, J. P; Castello, A. M. (2011). Historia. La segunda mitad del siglo XX. Serie: Huellas. Buenos Aires: Estrada.

\section{Notas}

1 En este trabajo distinguimos, dentro del género de los textos escolares, los manuales de los libros de textos. Se denomina manuales a los libros escolares que compendian las cuatro áreas o disciplinas (Lengua y Literatura, Matemáticas, Ciencias Sociales y Ciencias Naturales) y que generalmente son utilizados en el último ciclo de la Escuela Primaria. Por otro lado, la categoría de libros de texto incluye únicamente a aquellos que se circunscriben a un área determinada - en nuestro caso, los libros de texto de Historia - y que son utilizados en la Escuela Secundaria.

2 Este trabajo es resultado de una investigación enmarcada en el proyecto "Conciencia histórica, conciencia política y enseñanza de la historia. El siglo XX y la construcción de la democracia en Argentina en las narrativas de alumnos de $5^{\circ}$ año de escuelas secundarias de La Plata"(2018-2019) que contó con el financiamiento del Consejo Interuniversitario Nacional (CIN) por medio de las Becas Estímulo a las Vocaciones Científicas durante el período 2019.

3 Basta cotejar brevemente las posturas de algunos de los investigadores de Malvinas más destacados para constatar la variedad de métodos de aproximarse a este objeto de estudio y las conclusiones que cada uno extrae. Destacamos y sugerimos la lectura de los aportes de Vicente Palermo (2007) -desde sus estudios de politología- quien analiza las políticas argentinas que "precipitan" a la Guerra; las dos obras más significativas del historiador Federico Lorenz - Las guerras por Malvinas (2006) y Malvinas: una guerra argentina (2009) - donde se hace un recuento del discurso social de la época y las experiencias; y la obra de la antropóloga Rosana Guber (2001) quien se focaliza en analizar los factores de la construcción de Malvinas en tanto que causa nacional y la experiencia de la Guerra en el estudio del escenario bélico.

4 En el artículo 92, inciso B se propone como contenido curricular común a todas las jurisdicciones: "La causa de la recuperación de nuestras Islas Malvinas, Georgias del Sur y Sandwich del Sur, de acuerdo con lo prescripto en la Disposición Transitoria Primera de la Constitución Nacional” (Ley 26.206, 2006).

5 Por ejemplo, si durante la primera mitad del S XX el gobierno se encargaba de elegir qué manuales podían utilizarse y se priorizaba el renombre de la firma del autor como legitimación del texto, la desregulación de este ingreso termina por configurar los textos a la lógica de la oferta y la demanda: se busca lograr textos novedosos, atractivos, con contenido y que interpelen tanto a los docentes - por medio de la figura del promotorcomo a los padres.

6 La selección de corpus no pretende ser exhaustiva pero sí intenta ofrecer un panorama de las distintas y diversas propuestas editoriales en materia educativa en la provincia de Buenos Aires. De esta forma, la diversidad de perfiles editoriales fue uno de los criterios tenidos en cuenta a la hora de elaborar el corpus. Por ende, se incluyen tanto editoriales de origen extranjero -Santillana-, editoriales de origen nacional que han sido compradas por grupos extranjeros -Estrada, perteneciente al Grupo Macmillan desde 2007-, editoriales nacionales pertenecientes a grupos argentinos -Tinta Fresca perteneciente al Grupo Clarín - y editoriales nacionales independientes -editorial Maipue-. A su vez, este muestrario también compendia editoriales ya clásicas dentro de la producción de manuales y libros de texto - como Santillana y Estrada, con más de medio siglo de vigencia en el mercado y otras más bien recientes -Maipue es fundada en 1997 y Tinta Fresca comienza con la publicación de textos escolares en 2004-. En este estudio también un caso especial de licitación que manifiesta el ingreso del Estado en la producción y distribución de textos escolares después de algunas décadas apartadas de esta tarea. En el marco del Programa Textos Escolares para Todos impulsado por la Dirección General de Cultura y Educación (DGCyE), se convoca a un concurso para editar libros de texto correspondientes a distintas asignaturas de la Escuela Secundaria. La propuesta de Tinta Fresca obtiene el primer premio al libro de texto de Ciencias Sociales 3 (correspondiente a los contenidos de años superiores de 
Historia y Geografia). En ese caso, la edición y distribución estuvieron a cargo de la DGCyE. Estos libros han sido distribuidos a lo largo y a lo ancho de la Provincia de Buenos Aires durante el periodo 2007-2008.

7 En esta cita también se da la particularidad de referirse al desembarco como "invasión”, lo que implicaría que las Islas no pertenecen al territorio argentino. Excede el propósito de este trabajo adentrarnos en el reconocimiento de soberanía que se hace a partir de las representaciones de la Guerra. Estas y otras aristas - como el rol mediático y el esquema internacional - son desarrolladas en la tesina de la que se desprende este artículo.

8 La utilización de una construcción inergativa metafórica despertar+nacionalismo, en la que el sujeto (el nacionalismo) tiene un rol semántico pasivo en calidad de ser quien sufre la acción, pero no tiene agentividad en ella, coincide con la visión de nacionalismo acrítico que se promulga y que, como hemos expresado en el primer capítulo, se encuentra entre gran parte de los estudios académicos:

9 No obstante, ni en la versión del 2012 de Santillana ni en los libros de Maipue - si bien se menciona el Operativo Cóndor - se llega a hacer una reconstrucción del rol activo que ha tenido la sociedad argentina en la Guerra: ya sea recaudando para el Fondo Patriótico Malvinas Argentinas, escribiendo cartas y hasta ofreciéndose como voluntarios civiles para ser enviados a las Islas. Por el contrario, el apoyo popular aparece en los libros como un mero telón de fondo de la Guerra y, por ende, no ingresan en nuestra categoría de protagonistas.

10 Entendemos por subjetivemas a las elecciones léxicas que manifiestan una carga valorativa del enunciador respecto al hecho y, por lo tanto, su subjetividad.

11 Datos sistematizados por Matías di Santi y Martín Slipczuk para Chequeado.com. Disponible en: https://chequeado.com/el-explicador/guerra-de-malvinas-cuantas-pe rsonas-participaron-y-que-ocurre-hoy-con-los-veteranos/

12 Excepto en la edición de Estrada donde, si bien se hace mención a la superioridad británica (ver apartado siguiente) los combatientes son designados como "hombres" y no se profundiza en tópicos como la inexperiencia o la juventud y vulnerabilidad.

13 Una versión más matizada aparece en el libro de la DGCyE: "Murieron alrededor de 600 argentinos, en su mayoría jóvenes que cumplían con el servicio militar obligatorio" (Acuña y otros, 2007).

14 Respecto a estos puntos, recomendamos el trabajo de Cisilino, Larocca y Olmo (2020) “ «Si quieres saber cómo te fue en la guerra, pregúntale a tu enemigo» aportes británicos para pensar la Guerra de Malvinas" donde se problematizan algunas nociones estereotipadas sobre el conflicto terrestre a partir del estudio de las memorias de dos excombatientes británicos: el general de división Julian Thompson y el almirante John Foster "Sandy" Woodward.

15 Si atendemos a que la comprensión y escritura del género académico constituye una de las mayores problemáticas en los primeros años de la vida universitaria, los materiales pedagógico-didácticos trabajados en la Escuela Secundaria resultan vitales para revertir esto. 